\title{
As tecnologias computacionais contemporâneas e a educação: contribuiç̧̃es do ciborgue e dos objetos inteligentes
}

Contemporary computer technologies and education: the contributions of the cyborg and of smart objects

Las tecnologias computacionales contemporáneas y la educación: contribuciones del ciborg y de los objetos inteligentes

THIAGO MARCONDES SANTOS ${ }^{a}$

Edméa Oliveira dos SANTOS ${ }^{b}$

DENISE DEL RE FILIPPO ${ }^{c}$

\section{Resumo}

Neste artigo discutimos as tecnologias computacionais ubíquas e seus desdobramentos para a sociedade na área da educação. Refletimos, com base em nossa pesquisa (SANTOS et al, 2015), as implicações provocadas na educação através da possibilidade de novas práticas pedagógicas no processo de aprendizagem na escola do século XXI. Também utilizamos episódios da série Black Mirror para enriquecer nosso debate sobre a aprendizagem em tempos onde os conceitos de objetos inteligentes e ciborgues já estão presentes.

Palavras-chaves: Educação. objetos inteligentes. Ciborgues. Computação.

\footnotetext{
a Universidade Federal do Estado do Rio de Janeiro (UNIRIO), Rio de Janeiro, RJ, Brasil. Mestre em Sistemas de Informação pelo PPGI, e-mail: Thiago.marcondes@uniriotec.br

b Universidade Federal Rural do Rio de Janeiro (UFRRJ), Seropédica, RJ, Brasil. Doutora em Educação, email: edmeabaiana@gmail.com

' Escola Superior de Desenho Industrial (ESDI-UERJ), Rio de Janeiro, RJ, Brasil. Doutora em Engenharia de Software, e-mail: prof.denise.filippo@gmail.com
} 


\begin{abstract}
In this article, we discuss ubiquitous computer technology and its consequences to society, specifically in the field of education. Based on our research (SANTOS et al, 2015), we consider the implication on education of the possibility of new pedagogical practices in the learning process within twenty-first century schools. We also use episodes of the series Black Mirror to enrich our debate about learning in times when the concepts of smart objects and cyborgs are already present.
\end{abstract}

Keywords: Education. smart objects. Cyborg. Computing.

\title{
Resumen
}

En este artículo, nosotros discutimos las tecnologías computacionales ubicuas y sus consecuencias para la sociedad, más específicamente en el área de la educación. Consideramos, con base en nuestra pesquisa (SANTOS et al, 2015), las implicaciones en la educación de la posibilidad de nuevas prácticas pedagógicas en el proceso de aprendizaje en la escuela del siglo XXI. También utilizamos episodios de la serie Black Mirror para enriquecer nuestro debate sobre el aprendizaje en tiempos nos cuales los conceptos de objetos inteligentes y cíborgs ya están presentes.

Palabras-clave: Educación. Objetos inteligentes. Cyborg. Computación.

\section{A cibercultura em tempos de ciborgues e objetos}

\section{inteligentes}

Discutimos, neste artigo, os potenciais e implicações das novas tecnologias computacionais, mais especificamente a temática dos objetos inteligentes e do ciborgue, para compreendermos a educação na sociedade contemporânea. Neste contexto, preferiuse a metodologia multirreferencial de pesquisa (SANTOS, 2014). Num primeiro momento, buscamos apoio teórico na literatura especializada no campo da Computação e da Comunicação, mais especificamente nos estudos da Cibercultura. Optaram também pela análise fílmica, mais especificamente do artefato cultural, pós-cinema, difundido pela Netflix, a Série "Black Mirror", série formada por um conjunto de temporadas, onde diversos fenômenos da cibercultura são explorados. Buscamos episódios diretamente relacionados aos temas dos objetos inteligentes e do ciborque, uma vez que estes temas 
vem inspirando nossas pesquisas na interface com campos da Informática, Educação e das Artes. Tratamos o campo das Artes, a exemplo do Cinema, como uma legítima referência. Tais referências vem inspirando os autores do desenvolvimento de objetos inteligentes para disparar práticas educativas sintonizados com a cibercultura. Para este trabalho, apresentamos o projeto dos "Tapetes musicais inteligentes".

Com a disseminação/difusão da computação pelos ambientes e objetos do cotidiano, a sociedade passa a viver uma reconfiguração das relações entre os seres humanos e os objetos. Num primeiro momento, os objetos eram feitos para um determinado objetivo: um carro servia para se locomover de um ponto da cidade para outro, uma geladeira servia para preservar os alimentos, uma xícara servia para receber e conter um líquido. Agora, estes objetos são dotados de capacidades adicionais: o carro também informa ao seu motorista quais são as rotas mais rápidas para o destino escolhido, a geladeira percebe quando um determinado item está acabando e informa ao supermercado que uma entrega deve ser agendada e a xícara percebe se está vazia e envia uma mensagem para que a cafeteira prepare mais café. Gradativamente, os objetos do cotidiano estão ganhando habilidades que os colocam em uma nova configuração com a sociedade. Deixam de ser elementos meramente passivos à interação humana, para ocupar outra posição em um novo arranjo, em que podem perceber o ambiente à sua volta, agir neste mesmo ambiente e até se comunicar com outros objetos sem a necessidade da intervenção humana.

Weiser (1991) já antevia um mundo com microprocessadores, cada vez menores e mais poderosos, embarcados nos objetos do cotidiano. No cenário vislumbrado por ele, os dispositivos eletrônicos estão em todos os lugares (ubíquos) e em grande quantidade são conectados em rede e baratos; podem ser fixos ou móveis; e encontram-se embutidos em objetos que cercam a vida cotidiana, como fogões, geladeiras, telefones, bicicletas, entre outros. Esses dispositivos estão presentes no local em que são necessários, sendo discretos visualmente e em seu comportamento, de forma a só serem percebidos e atuarem quando necessário (FILIPPO; PIMENTEL; WAINER, 2011). Weiser chama a atenção para que esses objetos sejam concebidos seguindo o que ele denominou de Tecnologia Calma (WEISER e SEELY, 1996). A característica do objeto de atuar de forma calma, ou “invisível”, é importante para não sobrecarregar o indivíduo com informações, para não solicitá-lo a entrar com dados a todo momento, e para não gerar interrupções 
desnecessárias. O objeto deve atuar perifericamente no ambiente de forma que, quando desejado e de forma consciente, o indivíduo foca sua atenção nele.

Concomitantemente à hibridização dos objetos com as tecnologias computacionais, existe também a hibridização do próprio ser humano com tais tecnologias. Presenciamos uma nova era, em que diferentes arranjos entre o humano e o artificial são possíveis, implicando em uma revisão sobre o conceito de humano e de artificial, já que não há a nitidez nas fronteiras entre estas duas entidades. Se o uso de próteses para a substituição de membros perdidos já era um indício de mescla do humano com as máquinas, o que poderíamos dizer sobre o marca-passo, a hemodiálise, os corações artificiais ou as bombas eletrônicas de insulina? As máquinas — e aqui os computadores também são um exemplo — estão se conectando ao ser humano e possibilitando o surgimento de um novo tipo de ser que é ao mesmo tempo biológico e mecânico-computacional, também denominado ciborgue.

A Computação Ubíqua tem provocado uma mudança significativa não só nas relações entre humanos e objetos, mas também nas definições de humano e de máquina. $\mathrm{O}$ corpo humano tem se tornado mais artificial, e os objetos estão se tornando mais inteligentes computacionalmente. Em nossa história de civilização, por muito tempo não cogitamos a existência desse arranjo biológico-artificial, o que implica em repensarmos a relação entre o homem e a sua hibridização com os produtos tecnológicos por ele desenvolvidos. A evolução das tecnologias computacionais na sociedade tornou real o que antes era uma fantasia.

Atualmente, o imaginário da sociedade já expressa uma vasta gama de relações dos humanos com objetos inteligentes e com as redes computacionais de informação que se espalham pelo mundo. Corroboram com este argumento as inserções, cada vez mais frequentes, de ciborgues e objetos inteligentes nos roteiros de filmes e séries na atualidade.

Este artigo está organizado em 4 tópicos. Neste primeiro tópico “A cibercultura em tempos de ciborgues e objetos inteligentes", apresentamos o tema do ciborque e dos objetos inteligente na sociedade contemporânea, mais especificamente na vida cotidiana. No segundo tópico, mostraremos como a temática do ciborque e os objetos inteligentes são tratados na série Black Mirror, da Netflix. A cibercultura, contada por este artefato cultural, pode inspirar práticas pedagógicas em educação e disparar discussões plurais para 
o tratamento de diversos temas e reflexões educacionais em nosso tempo. No terceiro tópico “Objetos inteligentes, ciborgues e a pós humanidade", aprofundamos o debate à luz das discussões em torno do campo da "pós-verdade" e como esta discussão vem desafiando educadores na cibercultura. No quarto e último tópico, apresentamos o projeto de pesquisa e formação "Tapetes musicais", projeto desenvolvido do âmbito de uma pesquisa de doutorado que desenvolve metodologias de educação musical com artefatos digitais, mais especificamente os objetos inteligentes e tecnologia do ciborque. As mesmas tecnologias usadas para vigiar e controlar também podem inspirar inovadores projetos educacionais.

\section{Ciborgues e objetos inteligentes em Black Mirror}

A série Black Mirror possui 5 temporadas e retrata, com uma visão essencialmente distópica, como os avanços nas tecnologias de informação e comunicação, potencializando o lado sombrio do ser humano, podem servir de base para compreendermos o nosso tempo mediado pelo digital em rede, e no qual diferentes formas de controle e violência são possíveis. Os desdobramentos distópicos das tecnologias computacionais em nossa sociedade, tratados em todos os episódios, englobam exemplos como ciborgues, objetos inteligentes, redes de comunicação global, ciber-terrorismo, realidade virtual e aumentada, e consciência computacional, dentre outros temas contemporâneos sobre a computação e seus possíveis impactos negativos para a sociedade.

Além de mapear estes impactos negativos, nos interessa sobremaneira buscar inspirações para o desenvolvimento de projetos que lancem mão do potencial interativo e pedagógico para a educação em nosso tempo. Afinal, vivemos num momento singular da história da humanidade.

O episódio da primeira temporada, Toda a sua vida, dialoga com esta temática do ciborgue. No mundo retratado neste episódio, as pessoas podem adquirir um dispositivo computacional chamado de "grão", que tem o tamanho aproximado ao de um grão de arroz, e que, inserido na nuca, consegue captar imagens e sons vivenciados por seu usuário e projetá-los em qualquer tela eletrônica disponível, ou em um tipo de lente de contato que atua como um display para ver as imagens. Desta forma, os usuários podem gravar tudo o que vivenciam e posteriormente conferirem seus passados sem deixar escapar nenhum detalhe, se assim o quiserem. O período de gravação pode variar, mas existem planos de 
serviços de memória que permitem aos usuários gravar décadas de suas vidas pelo módico preço de uma xícara de café por dia. Um tipo de assinatura de sua própria memória. A tecnologia computacional representada por um artefato, o grão, se funde ao ser humano e traz novas capacidades para seu usuário exercendo profundas influências em sua vida. $O$ resultado é um ser híbrido entre o humano e o computacional. O episódio enfatiza que a maior parte das pessoas utiliza o implante, porém existem algumas poucas pessoas que preferem não usar esta tecnologia e outras, como o protagonista, que se arrependem de ter implantado o grão e posteriormente se encontram em um estado de grande desespero ao ponto de até mutilarem seus corpos para extrair o artefato.

A narrativa deste episódio apresenta as diferenças provocadas na vida do usuário do implante e, em nossa opinião, provoca o espectador no sentido de evidenciar o ciborgue como um passo dúbio no processo evolutivo do ser humano. As novas características e habilidades, oriundas da fusão humano tecnológico, em um primeiro momento nos tornam melhores, mas também cobram um preço que nem todos são capazes de suportar. Esses ciborgues não precisam se preocupar em guardar nada em suas memórias, pois, se preciso for, podem usar seu grão para ter a certeza de acontecimentos passados. Contudo, com o desenvolver da trama, este poder de memória conferido ao protagonista passa a ser fonte de angústia, já que o seu perfil ciumento e controlador começa a influenciar sua relação com sua esposa. Aqui, temos uma rica oportunidade de discussão em sala de aula e também na formação de professores, principalmente se contarmos com a contribuição dos estudos de gênero e educação. Tensionar sobre as noções de patriarcado, heteronormatividade, poderá render boas ambiências formativas.

O protagonista passa por uma espiral negativa de sentimentos e inquietações provenientes do poder mnemônico adquirido com o implante, e acaba se divorciando de sua esposa após saber de um encontro amoroso que ela teve com um outro homem. Mesmo após o divórcio ele não consegue se separar de seu passado e acessa continuamente as imagens de sua esposa na época em que suas vidas estavam em harmonia. Parece ser uma busca de apagar o presente com a sobreposição forçada de um tempo passado. Neste processo de recusa da realidade, o personagem principal chega ao clímax de angústia e ao fim do episódio retira o grão de sua nuca com um estilete. 
Lemos (2018), em sua reflexão sobre este episódio, afirma que a série discute mudanças tecnológicas que apontam para um futuro próximo no século XXI, mas utiliza uma estética cinematográfica proveniente do século XIX e XX, enfatizando a captura de informações visuais. Sua crítica faz sentido se considerarmos os outros tipos mais contemporâneos de instrumentos de vigilância do século XXI, como os algoritmos de busca da web que guardam muitas informações sobre as pessoas sem que seja necessária nenhuma captação de imagens, mas sim a captação dos rastros binários que tais pessoas deixam pela web, seja na produção de texto, áudio, vídeo, ou em suas transações econômicas.

Neste episódio nos chama a atenção o fato do ciborgue apresentado conseguir gravar, em termos visuais e auditivos, as experiências do passado sem ter sua percepção dos acontecimentos alterada. O filme gravado pelo grão é uma cópia fiel dos acontecimentos e não sofre nenhum tipo de distorção, ou possível manipulação, que possibilitasse a criação de algo que não ocorreu ou que possibilitasse a corrupção de alguma memória transformando-a em outro acontecimento. O próximo episódio a ser discutido tratará desta temática de alteração de percepções do ciborgue.

O quinto episódio da terceira temporada de Black Mirror, "Engenharia reversa", tem o ciborgue como tema central. O implante, chamado de máscara, exerce diferentes implicações em seus usuários, que neste caso são soldados a serviço de um poder dominante. A máscara possibilita a comunicação e interação dos soldados numa espécie de realidade aumentada onde plantas de construções e dados topográficos de áreas de combate podem ser projetadas em suas retinas. O implante também altera sentidos como o olfato, a audição e a visão, manipulando a percepção da realidade e transformando os soldados em máquinas de extermínio de inimigos. Assim, o poder dominante cria, com o apoio do implante, uma narrativa que constrói um inimigo da sociedade, chamado de Barata, que deve ser erradicado.

As Baratas se apresentam aos sentidos dos soldados ciborgues como seres bípedes, mas aparentemente não humanos. São também horríveis e com dentes afiados, emitem gritos e não conseguem se comunicar. Ao entrar em combate com as Baratas os soldados também não sentem o cheiro do sangue derramado nas batalhas e todas estas distorções sensoriais visam a diminuir ou até erradicar a empatia dos soldados com o inimigo e, consequentemente, evitar a culpa de matá-los. O implante também possibilita ao poder Rev. Diálogo Educ., Curitiba, v. 19, n. 62, p. 987-1009, jul./set. 2019 
dominante criar recompensas para os soldados que se destacam nas missões planejadas por seus superiores. Para isso, os combatentes têm sua atividade onírica alterada para experimentarem sonhos eróticos após obterem sucesso em suas missões. No mundo descrito no episódio, as Baratas são caçadas pelos soldados ciborgues e estes também recebem apoio de aldeões que, apesar de não possuírem implantes, também são influenciados por uma narrativa calcada nos meios tradicionais de comunicação do poder dominante, que induz o combate a um inimigo projetado segundo interesses de dominação. Lemos (2018), ao refletir sobre este episódio, chama a atenção para o motivo do ciborgue presente na trama, mas aprofunda a discussão sobre o tema evocando dois conceitos diferentes de ciborgues. O ciborgue protético e o ciborgue interpretativo.

Para Gray e coautores (1995), o ciborgue protético é aquele em que há a combinação do ser orgânico com tecnologias e objetos micro-eletrônicos, enquanto o ciborgue interpretativo é aquele que tem suas consciências formadas com base na linguagem simbólica e nas mídias e em toda forma de comunicação mediada. Assim, temos os dois tipos de ciborgues na trama, pois os soldados são ciborgues protéticos — próteses tecnológicas conjugadas a seus corpos para alterarem seus sentidos e atividade onírica - e interpretativos — já que também recebem informações do poder dominante em discursos tradicionais como a propaganda contra um inimigo em uma narrativa construída. Os aldeões são apenas ciborgues interpretativos, uma vez que são expostos à propaganda contra um inimigo fabricado pelo discurso do poder dominante.

O episódio também mostra um humano que se rebela contra as intenções do poder vigente, criando um artefato que emite uma luz e envia um tipo de vírus, que altera o funcionamento da máscara dos soldados. Este vírus gradativamente atua bloqueando as alterações sensoriais dos soldados ciborgues, representando uma tática de guerrilha dos oprimidos contra as estratégias dominantes. Desta forma, não podemos deixar de comentar que a tecnologia pode tanto servir a propósitos nefastos de vigilância, controle e punição como também pode ser usada para fins libertários e ativistas.

Observamos neste episódio um exemplo extremo de falsa narrativa que, apoiada em tecnologias que alteram os sentidos humanos, possibilita aos comandantes do exército manipular seus soldados ciborgues para que estes sigam suas ordens sem questionamentos. Em tempos de discussão sobre a pós-verdade e as fake news, este episódio chama nossa 
atenção sobre uma exacerbação da falsa narrativa que não se apoia apenas no uso da linguagem simbólica, mas sim nas implicações que as faculdades sensoriais têm sobre a percepção da realidade na sociedade. Ao trabalhar com a percepção dos indivíduos em um nível sensorial, pela escuta, visão e olfato, a máscara parece blindar o soldado de qualquer questionamento, pois é criada uma falsa realidade, que é possível pela fabricação de fatos apoiados nos sentidos humanos. Os sentidos dos soldados assumem um papel de avalistas da situação. Existe na sociedade, há muito tempo, a crença de que se sentimos algo este algo deve de fato existir e ser verdadeiro. A relação da sociedade com seus sentidos, principalmente a visão, vêm de longa data e a máxima de São Tomé, "Ver para crer", ainda é usada hoje em dia. Assim, o episódio tenciona os possíveis rumos que as narrativas na sociedade podem tomar em um futuro. Ao refletirmos sobre essa questão, surge uma pergunta: se, por um lado, uma notícia falsa pode ser verificada e desconstruída, como fazemos se os sentidos humanos são alterados e você passa a ouvir, ver e sentir o cheiro da mentira? Diante da realidade apresentada no episódio, em que os sentidos podem sofrer uma reconfiguração, percebemos o quão frágil se tornam os conceitos de realidade e verdade e como nossa relação com as tecnologias pode ter consequências perigosas.

Outro episódio, o sexto da terceira temporada, chamado Odiados pela nação, aborda os objetos inteligentes com a miniaturização de computadores que possibilita a criação de abelhas robôs. No episódio, as abelhas da natureza estão acabando por uma razão não bem compreendida pelos cientistas, que desenvolvem as abelhas robôs para substituir as naturais no processo de polinização de lavouras ao redor do mundo. Diante de uma potencial crise na agricultura do planeta, os pequenos robôs abelhas são usados como parte da solução, mas como estão conectadas com a web, também são programadas à distância para serem usadas com outras finalidades, como a vigilância de pessoas. Neste episódio um cientista escreve um manifesto que tem por objetivo orientar a sociedade das consequências nefastas do desenvolvimento tecnológico. Para ele, a sociedade não tem noção do poder e da destruição que o desenvolvimento tecnológico pode causar. Então, ele usa as abelhas robôs para mostrar a fragilidade da sociedade em relação às tecnologias computacionais e também em relação a seus próprios medos e falhas, como no caso dos crimes de ódio na internet. O cientista consegue reprogramar as abelhas de forma a atacarem uma determinada pessoa, baseadas em publicações de ódio na web. As abelhas robôs são acionadas com base nas 
publicações da internet e, como têm micro câmeras e um software que faz reconhecimento facial, conseguem caçar a pessoa escolhida até matá-la.

Lemos (2018) reflete sobre este episódio destacando o papel crescente dos objetos inteligentes na construção da Internet das Coisas e a sua relação com a sociedade. $O$ autor também chama nossa atenção para os problemas de vigilância e os potenciais riscos de hackeamento de sistemas para fins de dominação e punição. Ele considera que os argumentos colocados na trama já evidenciam um olhar do nosso presente que aponta para o futuro, ao contrário dos outros episódios onde este olhar se baseava em uma estética do passado, ainda que vestido com tecnologias futuristas.

A abelha robô é uma mescla entre as tecnologias computacionais e um objeto, sendo ela capaz de: sentir o ambiente à sua volta (reconhecendo as suas vítimas), se comunicar com outras abelhas robôs e com aplicações disponíveis na Internet (sabendo o paradeiro de suas vítimas através da mineração de dados que estão disponíveis na rede) e atuar no ambiente (matando as vítimas). Diante destas características, consideramos as abelhas robôs como objetos inteligentes. Elas não são ciborgues, pois não há uma mistura de tecnologias e elementos computacionais com partes do inseto abelha. O que ocorreu foi a inspiração de um inseto pela construção de um objeto inteligente capaz de realizar algumas das ações que uma abelha consegue fazer. O robô abelha pode voar, polinizar lavouras, se comunicar com outros robôs abelhas e até atacar pessoas, mas todas estas ações estão programadas num software. A capacidade de simulação de uma abelha tem limitações e nos fez pensar que, mesmo com o avanço tecnológico, ainda existem limites que qualquer tecnologia enfrenta em uma determinada época. Estas abelhas robôs podem caçar e matar uma pessoa com base em informações presentes na Internet, mas não são capazes de produzir mel.

Ao refletirmos sobre os 3 episódios apresentados, nos parece importante ressaltar que as narrativas dos episódios evidenciam o lado sombrio e potencialmente perigoso da utilização de tecnologias computacionais pela sociedade, sejam com ciborgues, sejam com objetos inteligentes. O que aconteceria se o protagonista do episódio Toda a sua vida não fosse inseguro, violento e controlador? E se a tecnologia de alteração dos sentidos no episódio Engenharia reversa fosse utilizada para tratar fobias ao invés de alimentá-las? E se as 
abelhas robôs de Odiados pela nação fossem programadas para a detecção de desastres naturais como incêndios, enchentes ou terremotos?

Poderíamos realizar um exercício imaginativo em que os usuários das tecnologias computacionais de um futuro próximo pensem a vida como algo valioso e a ser preservado. Consequentemente criariam ferramentas e interfaces que poderiam promover o bem da humanidade. Os avanços tecnológicos despertam em nossa imaginação algumas dúvidas e receios e, por isso, é muito importante que a sociedade debata com profundidade e de maneira muito responsável as implicações de certas tecnologias antes de sua operacionalização. O avanço das tecnologias computacionais e sua inserção no cotidiano da sociedade não precisa necessariamente passar pelo arquétipo futurista distópico, já consagrado em livros e roteiros de filmes como Metrópolis, de Fritz Lang e Thea von Harbou (1927), Admirável mundo novo, de Aldous Huxley (1931), 1984 de George Orwell (1949) e Blade Runner de Hampton Fancher e David Peoples (1982).

\section{Objetos inteligentes, ciborgues e a pós humanidade}

As relações entre os seres humanos, os objetos e o ambiente estão mudando em um ritmo acelerado. Tais mudanças implicam em um questionamento dos conceitos do que é humano, objeto, e até mesmo ambiente, uma vez que a fronteira que antes separava estes agentes está cada vez mais imprecisa. Nesta recente realidade, o orgânico se mistura ao computacional e seres humanos modificam seus corpos através do uso de próteses tecnológicas mais avançadas, que possibilitam mudanças em sua qualidade de vida.

\section{O ciborgue: origens e implicações}

O termo cyborg surge, pela primeira vez, em um artigo da revista norte americana Austronautics (CLYNES e KLINE, 1960). Neste artigo, os autores, médicos e pesquisadores do hospital Rockland Estate em Orangeburg N. Y. argumentam que, para as extremas condições de uma viagem espacial, deveriam ser tomadas medidas que possibilitassem a sobrevivência dos astronautas em ambientes que em nada se assemelhassem aos do planeta Terra. Para enfrentar as longas viagens, os astronautas deveriam ter ao seu dispor formas de regular substâncias químicas em seus organismos Rev. Diálogo Educ., Curitiba, v. 19, n. 62, p. 987-1009, jul./set. 2019 
para, por exemplo, entrarem em hibernação durante maior parte da viagem. O estoque de oxigênio para tais viagens também seria um problema logístico, devido ao seu peso e espaço ocupado. Surge então a necessidade de se repensar como interagir e alterar de forma automatizada as funções vitais humanas.

Clynes e Kline (1960) então forjam, pela primeira vez, o termo Ciborgue que é resultado da junção entre Cibernética e Organismo, sendo Cibernética definida como a ciência de comunicações e sistemas de controle automático em máquinas e seres vivos (OXFORD DICTIONARY, 2018). Em um estudo conhecido como o Rato de Rockland, os pesquisadores acoplam uma microbomba hormonal sob a pele de um rato para que esta injete substâncias químicas a uma taxa administrada pelos pesquisadores. Pela primeira vez na história da ciência, um organismo tem suas características e comportamento alterados no nível químico por um artefato auto regulador inserido em seu corpo, surgindo assim o primeiro ciborgue.

Pode-se dizer que o experimento do Rato de Rockland é um antecedente distante das bombas eletrônicas de insulina que hoje conferem maior qualidade de vida a muitos seres humanos com diabetes. Este fato vem reforçar as possibilidades de uso das novas tecnologias computacionais no cotidiano da sociedade. Como afirma Donna Haraway em seu manifesto ciborgue:

No final do século $X X$, neste nosso tempo, um tempo mítico, somos todos quimeras, híbridos - teóricos e fabricados - de máquina e organismo; somos, em suma, ciborgues (HARAWAY 1985, p. 39).

\section{Humanos, máquinas ou pós-humanos?}

Há uma aproximação cada vez mais intensa entre estes dois elementos, que já tiveram suas fronteiras bem delimitadas no passado: de um lado, o ser humano e suas emoções e consciência; de outro lado, as máquinas e sua natureza inerte. Atualmente estes dois extremos se aproximam e formam um campo de estudo novo que precisa lidar com realidades que, em um passado não muito remoto, eram impensáveis.

As máquinas do final do século $X X$ tornaram completamente ambígua a diferença entre 0 natural e o artificial, entre a mente e o corpo, entre aquilo que se autocria e aquilo que é 
externamente criado, podendo-se dizer o mesmo de muitas outras distinções que se costumavam aplicar aos organismos e às máquinas. Nossas máquinas são perturbadoramente vivas e nós mesmos assustadoramente inertes (HARAWAY, 1985, p. 42).

Lucia Santaella também se ocupa da temática referente a estes arranjos que desafiam os conceitos de natural e fabricado, de organismo e máquina, mas prefere utilizar o termo biocibernético a ciborgue:

O sentido que dou a essa palavra "biocibernético" é similar ao de "ciborgue" Entretanto, prefiro o termo "biocibernético", de um lado, porque "bio" apresenta significados mais abrangentes do que "org", e, de outro lado, porque "biocibernético" expõe a hibridização do biológico e do cibernético de maneira mais explícita, além de que não está culturalmente tão sobrecarregado quanto "ciborgue" com as conotações triunfalistas ou sombrias do imaginário fílmico e televisivo (SANTAELLA, 2007, p. 130).

Apesar de haver diferenças nas escolhas etimológicas entre Santaella e Haraway, ambas estão refletindo sobre novas implicações da mistura entre o humano e tecnologia. Elas reconhecem que há uma ruptura na história da humanidade que caminha para algo indefinido e que traz grandes impactos ao nosso mundo. Santaella denomina este devir como o pós-humano.

Tenho buscado evidenciar o papel que a transformação tecnológica do corpo vem desempenhando para a emergência do pós-humano, este entendido não só como resultado dessas transformações, mas, sobretudo, como desconstrução das certezas ontológicas e metafísicas implicadas nas tradicionais categorias, geralmente dicotômicas, de sujeito, subjetividade e identidade subjacentes às concepções humanistas que alimentaram a filosofia e as ciências do homem nos últimos séculos e que hoje, inadiavelmente, reclamam por uma revisão radical (SANTAELLA, 2007, p. 136).

É importante lembrar que as tecnologias não apenas se fundem ao corpo humano, mas também se espalham pelo espaço das cidades e locais onde os humanos habitam e vivem, sejam estradas, lojas, aeroportos, suas casas, e objetos do cotidiano, como geladeiras, relógios e aspiradores de pó.

A miniaturização e o barateamento de componentes eletrônicos, a disponibilização de diferentes soluções de redes sem fio, o amadurecimento das tecnologias relacionadas a redes de sensores. a possibilidade de identificação de objetos e pessoas por meio de RFID (etiquetas eletrônicas encontradas, por exemplo, em cartões para uso em transporte público), reconhecimento de características físicas e movimentos (face, digital, íris, gestos) e o desenvolvimento de novos materiais são fatores que possibilitam e potencializam o cenário da computação pervasiva ou ubíqua e a Internet das Coisas, que está espalhada por todo o espaço de vivência da sociedade (FILIPPO; PIMENTEL; WAINER, 2011).

Já para Kaku:

Os prognósticos atuais, no campo emergente da computação "pervasiva" ou onipresente, indicam com alguma segurança que nossos estilos de vida serão fatalmente alterados quando 
os microchips se tornarem tão abundantes que sistemas inteligentes serão espalhados aos milhões em todo canto de nosso ambiente, incorporados às paredes, aos móveis, aos nossos aparelhos, nossa casa, nosso carro, penetrando na estrutura de nossas vidas (KAKU, 2001, p. 29).

\section{O que são objetos?}

A Computação Ubíqua, como mencionado anteriormente, é possibilitada pela miniaturização de computadores que podem ser embarcados em objetos tornando estes capazes de novas formas de interação com o ambiente e as pessoas a sua volta. Antes de pensar nas mudanças dos objetos, precisamos entender melhor o que são objetos. Lemos (2013) afirma que:

A existência dos objetos é só em parte percebida pela nossa experiência. Objetos estão sempre associados a outros objetos e a outros componentes que formam a sua estabilidade como caixas pretas. Uma xícara, um computador, uma caneta bic são exemplos compostos de muitos outros objetos, remetendo a funções e experiências diversas que se estabilizam em uma unidade (LEMOS, 2013, p. 245-246).

Desta forma, Lemos sugere que não se pode revelar os segredos dos objetos em si, mas podemos ver suas trajetórias e compreendê-las nas associações que ocorrem com estes objetos.

\section{Objetos inteligentes}

Com a Computação Ubíqua, os objetos tornam-se "smart" ou, no Brasil, “inteligentes", na medida em que eles deixam de ser inertes e que eles (re)agem ao ambiente por meio de comportamentos determinados pelo harware e software a eles associados (FILIPPO; PIMENTEL; WAINER, 2011). Acoplados a microcontroladores, sensores, motores, luzes e caixas de som, os objetos ampliam suas relações com o mundo à sua volta.

López et al. (2011) buscam desenvolver uma forma para organizar os objetos inteligentes segundo um conjunto de propriedades que são representadas por um código de letras relacionadas a seguir: 
I- Identidade - o objeto deve ter uma identidade única para permitir sua identificação em diferentes contextos de relações com outros objetos inteligentes e sistemas computacionais.

S- Sensoreamento - o objeto deve sentir, através dos mais variados sensores, as características do ambiente onde estão inseridos e sua relação com esse ambiente.

A- Atuação - o objeto deve atuar sobre o ambiente onde se encontra, segundo regras que podem ou não depender dos dados obtidos em uma etapa sensorial.

D- Decisão - o objeto deve ser capaz de decidir, segundo regras especificadas, como irá reagir e atuar em determinadas situações após a fase sensorial.

N- Networking ou atuação em rede - o objeto deve poder se comunicar com outros objetos ou com sistemas computacionais e poder assim ampliar sua área de sensoriamento e atuação (de entrada e de saída de dados).

É importante ressaltar que neste conjunto de características não é necessário que todas as propriedades estejam reunidas em um único objeto. Um objeto pode ser inteligente possuindo apenas um subgrupo destas propriedades, ou também pode se juntar a outros objetos que possuem outras propriedades que o primeiro objeto não tem e, assim, formarem um sistema mais complexo com a soma de diferentes propriedades.

Com base nas características apresentadas, podemos agora pensar as novas relações ou associações entre os seres humanos e os objetos inteligentes do século XXI. Consideramos que tais associações promovem o surgimento de ciborgues em diferentes ambientes de nossa sociedade. As novas capacidades info-comunicacionais conferem, por exemplo, ao carro - aquele objeto que conhecemos como um conjunto de chassi, motor, bancos, carroceria - a capacidade de consultar uma rede de dados de trânsito e perceber quais são as melhores rotas para que seu motorista não fique preso no engarrafamento. Observamos aqui uma grande mudança com relação ao que um carro é capaz de fazer nos dias atuais. Apesar de, para nós, o carro estar sensorialmente igual (LEMOS, 2013) visual, tátil, auditiva e até olfativamente - ele agora nos dá conselhos baseados no estado do ambiente num determinado momento que nos fazem pensar e refletir sobre mudanças em nossas ações. Por outro lado, o motorista deste carro também é alterado, pois sabe que pode contar com conselhos sobre o trânsito que o possibilite levar menos tempo para chegar ao trabalho e assim poder passar mais tempo com seu filho. Percebemos aqui um Rev. Diálogo Educ., Curitiba, v. 19, n. 62, p. 987-1009, jul./set. 2019 
arranjo entre o carro e seu condutor onde surge um ciborgue temporário, uma vez que o motorista não estará sempre dentro de seu carro, mas quando isso ocorre ele está adquirindo novas capacidades provenientes da associação do humano com um objeto inteligente. Tal fato nos leva à reflexão de que a sociedade do século XXI está repleta de ciborgues, sejam interpretativos, sejam protéticos permanentes ou temporários. As pessoas e seus celulares são outro exemplo de ciborgue protético temporário, enquanto os usuários de marcapassos ou bombas eletrônicas de insulina são ciborgues protéticos permanentes.

Com tantas possibilidades apresentadas, nos questionamos: como está sendo feita a absorção, pela escola, das tecnologias presentes no pós-humano? A seguir apresentamos o projeto dos "tapetes musicais inteligentes" e seus desdobramentos para a educação musical.

\section{“Tapetes musicais inteligentes", objetos inteligentes na educação com ciborgues}

Os autores deste artigo compartilham a visão de que a tecnologia computacional pode ser usada para melhorar a vida da sociedade. Por este motivo, nosso otimismo nos guia na direção de pesquisar e desenvolver artefatos que possam contribuir para o desenvolvimento de novas relações entre professores e estudantes dentro da sala de aula.

Tendo em vista este cenário pós-humano revolucionário e fecundo de perguntas e potencialidades, inevitavelmente a escola e as formas de aprendizagem também são impactadas. Surgem então algumas perguntas:

- Como a educação acompanha estas mudanças?

- Como as novas tecnologias computacionais entram no espaço escolar e contribuem para a melhoria da aprendizagem?

- Como as novas tecnologias computacionais apoiam os espaços educacionais?

Os "Tapetes Musicais Inteligentes" trata da pesquisa que realizamos para a dissertação de mestrado em Sistemas de Informação de um dos autores, Santos (SANTOS; PIMENTEL; FILIPPO, 2016), realizada no Programa de Pós-graduação em Informática da UNIRIO. Nesta pesquisa desenvolvemos um objeto inteligente: os Tapetes Musicais 
Inteligentes. Este objeto inteligente possibilitou a investigação de novas formas de atividades educacionais musicais no contexto da sala de aula e também possibilitou uma investigação de conjecturas teóricas sobre a educação musical. Foram realizadas oficinas pedagógicas com turmas de sétimo ano do Ensino Fundamental 2 em duas escolas municipais do Rio de Janeiro.

O artefato que desenvolvemos é composto de pisos de borracha, um software e um hardware que, combinados, possibilitam a produção sonora de forma facilitada e sem as demandas de aprendizagem da técnica, características dos instrumentos musicais tradicionais. Os estudantes posicionavam-se em duplas sobre pares de tapetes e, quando encostavam um no corpo do outro, seu contato era percebido pelo tapete inteligente que, por sua vez, acionava sons programados para tocar em um computador na mesa do professor. Desta forma, cada dupla de estudantes era responsável pela produção de um som, que poderia ser reconfigurado pelo professor no programa que estava instalado no computador.

Neste projeto de objetos inteligentes e sua aplicação na escola, tapetes de borracha coloridos, usados tipicamente em creches e escolas, foram combinados com uma placa eletrônica específica (MAKEY MAKEY, 2018) e um computador de maneira a mudar suas propriedades e possibilitar o apoio pedagógico a professores e estudantes nas aulas de música. O objeto, tapete, passa a receber habilidades info-comunicacionais e muda sua relação com os agentes do processo: professores, estudantes e direção da escola, além de pesquisadores. Por meio deste objeto inteligente, os estudantes conseguiam produzir sons de instrumentos que demandam um extenso processo de aprendizagem técnica, da ordem de meses, em questão de minutos. A colaboração entre estudantes é intensificada, pois, ao se tocarem fisicamente, os estudantes produzem os sons que são usados no discurso musical nas atividades em sala de aula. O uso do corpo e de gestos dos estudantes também é incentivado devido às características de produção sonora do artefato. Desta nova relação com os tapetes, os estudantes percebem o surgimento de habilidades que antes não eram cogitadas, como fazer música com gestos e o uso do corpo de maneira colaborativa em sala de aula. O processo de produção sonora tornou-se mais fácil, divertido e incentivou os estudantes a explorarem o discurso musical em sala de aula (SANTOS, PIMENTEL e FILIPPO, 2016). 
Os relatos dos estudantes nas entrevistas realizadas, após três meses usando os Tapetes Musicais Inteligentes, demonstraram como sua relação com este objeto do cotidiano, após ser modificado pela inserção de tecnologias computacionais ubíquas, se alterou. Para alguns, a aprendizagem tornou-se mais divertida através do surgimento de uma novidade:

"Para mim é um instrumento novo que eu gostei, muito muito muito!!"

"Eu achei legal e diferente porque nunca usei um instrumento com tapetes e movimentos para fazer som".

Para outros, houve uma sensação de magia neste processo, onde o objeto inteligente possibilitou a percepção de que seus corpos é que estavam produzindo os sons. Por alguns momentos os estudantes esqueciam do tapete, como se este fosse invisível para eles. Essa é uma característica importante de um objeto inteligente e que está fundamentada no conceito de Tecnologia Calma de Weiser (WEISER e SEELY, 1996). Um estudante até passou a ver seu corpo como um instrumento musical:

"Eu aprendi que eu posso fazer música com as mãos".

"No primeiro momento eu achei que não ia dar certo. Eu, fazer música com as mãos!! (risos) ai depois eu fui vendo que é bem divertido e legal e a gente aprende".

Para outros foi mais fácil produzir sons comparativamente aos instrumentos musicais tradicionais:

"Aqui é mais fácil. As notas já vêm praticamente prontas. Lá (instrumentos tradicionais) não, a gente tem que saber as notas de cor. Aqui achei muito mais fácil sim".

"É mais fácil. Temos de usar as mãos e é mais fácil do que os outros instrumentos, que a gente precisa de mais aprendizado"; "a gente não precisa fazer tanta coisa, só usar as mãos".

"Achei fácil porque as notas já vêm praticamente prontas e também temos a ajuda do professor e lá [aula de música tradicional] tem mais dificuldade porque ainda tem que preparar as notas".

Houve também surpresa e deleite, pelo uso do corpo e da colaboração entre estudantes de maneira diferente, no processo de aprendizagem musical.

"Eu aprendi a ... meio que abstrato o som que a gente fez lá porque a gente conseguia se divertir, brincar, pular e tocar no outro. Várias coisas diferentes que eu nunca tinha visto antes".

"Eu aprendi os ritmos com movimentos do corpo". 
"Eu aprendi a coordenação motora e o tempo de cada nota (gestos de baterpalmas). A sincronização é esperar o momento certo de bater".

Diante das afirmações dos estudantes, podemos tecer considerações sobre como os Tapetes Musicais Inteligentes influenciaram as relações entre estudantes, professores e aprendizagem musical na sala de aula. Primeiramente, destacamos como as mudanças introduzidas nos tapetes apoiaram a aprendizagem ao criar nos estudantes indagações e mudança nas relações destes com seus corpos e com os corpos de seus colegas no ambiente da sala de aula. A inteligência inserida ao objeto tapete possibilitou que os estudantes colaborassem uns com os outros, criassem estratégias de movimentos corporais e produzissem som de forma mais simples para a construção do discurso musical. As implicações do uso dos movimentos corporais e da colaboração entre estudantes são profundas e destaco aqui três questões:

A primeira questão diz respeito ao incentivo aos movimentos corporais e à colaboração entre estudantes: o objeto inteligente coloca os mesmos em uma posição de protagonismo dentro do processo de aprendizagem. Percebemos uma modificação no comportamento dos estudantes com a inversão do que usualmente se pratica nas escolas: em vez de um "corpo dócil” (FOUCAULT, 2014), imobilizado, aprisionado pela carteira, nas oficinas o corpo estava livre e era um meio importante para o aprendizado.

A segunda questão é relacionada ao cuidado dos estudantes com seu próprio corpo e o contato físico com o corpo do outro, conforme afirma um dos professores, da escola Operário Vicente Mariano. Esta escola localiza-se em uma área com grandes índices de violência, o complexo da Maré. Na entrevista concedida, o professor informou um fato relevante sobre o perfil dos estudantes da região.

"os alunos, principalmente ali na Maré, os alunos têm um problema muito sério com o contato físico. Às vez̧es eles são muito violentos. E aquela atividade eles têm de entender que tem de ter uma dosagem da força e eles têm que trabalhar em equipe também."

As questões dos estudantes com o contato físico podem ser trabalhadas com o uso de uma ferramenta que incentiva esse contato de forma lúdica e colaborativa, constituindose em importante instrumento, não apenas musical e de aprendizagem, mas também como instrumento de harmonização social entre os estudantes.

A terceira questão se refere ao atendimento aos alunos em turmas com grande quantidade de estudantes e poucos recursos. O professor da turma relatou: 
"Tenho turmas com média entre 38 a 45 alunos. Sempre acima de 40 e fica difícil atender em 50 minutos em um tempo e na verdade eu pego dois tempos com cada turma. Fica difícil atender todos ao mesmo tempo".

Com relação a esta informação do professor, os tapetes inteligentes também oferecem apoio para as dinâmicas em sala de aula pelo fato de se produzir sons a partir do contato entre duplas de estudantes. Com dez duplas instaladas, podemos fazer o revezamento entre quarenta estudantes com dois rodízios de estudantes nos tapetes. Desta forma, potencializamos o tempo da aula nas atividades de aprendizagem dos estudantes e também facilitamos a realidade do professor. Nas oficinas foram realizadas montagens de até 10 pares de tapetes e a troca de estudantes entre as atividades não levou mais que 1 minuto, pois a disposição física dos tapetes permite o livre movimento de estudantes pela sala de aula.

Como afirma Lemos (2013), os objetos participam de redes de associações onde não há separações precisas. Os Tapetes Musicais Inteligentes fazem parte de associações que possibilitam mudanças nas dimensões pedagógica e social dos estudantes nesta escola. As oficinas promovidas na pesquisa produziram situações onde foram percebidos indícios das associações entre objeto inteligente como mediador entre os professores, os estudantes, seu aprendizado e sua relação social no ambiente da sala de aula.

Também observamos que, devido à natureza tecnológica envolvida na configuração dos tapetes e à produção sonora dos estudantes através dos toques de suas mãos, vemos o conjunto tapetes/estudantes como um ente único, um ciborgue protético temporário coletivo. Os estudantes muitas vezes nem percebiam que estavam sobre os tapetes e que era aquele artefato, somado aos seus corpos, que produzia os sons. Para alguns estudantes suas mãos estavam produzindo os sons, o que evidencia a invisibilidade do artefato no processo de produção sonora e seu atendimento ao conceito de Tecnologia Calma. Esta invisibilidade do objeto inteligente pode ser muito relevante para que se evite a distração dos estudantes no processo de aprendizagem apoiada por tecnologias computacionais. Nosso artefato não possui telas para os estudantes assistirem nada. Toda a dinâmica se passa sem que os estudantes estejam passivos e prostrados na frente de um monitor; ao contrário, eles estão se movendo e se tocando, mas sem estímulos eletrônicos e visuais que possam causar distração no processo de aprendizagem. Desta forma, o artefato nos 
possibilita uma experiência para os alunos em sala de aula que oferece uma possibilidade alternativa ao conceito de corpo dócil de Focault (2014).

Pelo fato de os tapetes terem sido projetados para uso em grupo, este objeto inteligente, o ente único formado por tapetes/estudantes, vai além de um ciborgue protético temporário, ele é um tipo de ciborgue protético temporário coletivo.

\section{Considerações finais}

A reflexão sobre as novas relações entre os seres humanos e os objetos e tecnologias do Pós-Humano tem como consequência o reconhecimento de que podemos usar estes elementos para ações diversas e, por vezes, antagônicas. Tais ações podem apoiar o controle e o domínio da sociedade, mas também podem ser focadas na melhora da qualidade de vida da sociedade e criar condições libertárias.

Vislumbramos com entusiasmo um futuro que já tem raízes bem fincadas no presente e que trará importantes desdobramentos de melhorias na forma como a escola é percebida pelos estudantes, seus responsáveis e professores. O ambiente escolar, desde a sala de aula até a portaria, passa por mudanças que são a base de uma nova escola, a escola ciborgue. Neste novo cenário, uma rede de diferentes objetos inteligentes conectados à internet por meio principalmente dos celulares dos estudantes e professores apoiarão a aprendizagem e a mudança de comportamento e de estruturas hierárquicas que não atendem mais aos anseios dos ciborgues que somos no século XXI. Desta forma, veremos mudanças nos objetos e sujeitos da escola de um passado que não tem mais como servir ao presente e ao futuro. Como consequência deste processo, de amadurecimento da sociedade, surgirá uma escola onde também será difícil delinear as fronteiras entre os objetos e os sujeitos, necessitando assim de uma nova terminologia e novas formas de se pensar a educação. Muitas questões ainda estão por surgir e a sociedade navegará por águas turbulentas que, com muito movimento, não deixarão nada no mesmo lugar.

A pesquisa de dissertação de mestrado Santos et al. (2015) foi aprovada pelo comitê de ética da UNIRIO - Número do Parecer: 893.135. Data da Relatoria: 26/11/2014. 


\section{Referências}

CLYNES, M. E.; KLINE, N. S. Cyborgs and Space. Astronautics, sept. 1960.

FILIPPO, D.; PIMENTEL, M.; WAINER, J. Mobilidade e ubiquidade para a colaboração. PIMENTEL, M.; FUKS, H. (Orgs.). In: Sistemas Colaborativos. Rio de Janeiro: Ed. Elsevier, 2011. (Capítulo 18, p. 294-313). Disponível em:

<https://www.dropbox.com/sh/ftcq79y2aqq16u4/_sFxQwE8iO>. Acesso em: 20 de nov. 2018.

FOCAULT, M. Vigiar e punir. Lisboa: Leya, 2014.

GRAY, C. H. et al. The Cyborg Handbook. New York: Routledge, 1995.

HARAWAY, D., KUNZRU, H., Antropologia do ciborgue as vertigens do pós-humano. Trad. e org. Tomaz Tadeu. Belo Horizonte: Editora Autêntica, 2000.

HARAWAY, D. A Cyborg Manifesto: Science, Technology, and Socialist-feminism in the Late Twentieth Century, in Simians, Cyborgs, and Women. The Reinvention of Nature. New York: Routledge, 1985. p. 149-82.

KAKU, M. Visões do Futuro. Como a Ciência Revolucionará o Século XXI. Trad. Maria Luiza X. de A. Borges. Rio de Janeiro: Rocco, 2001.

LEMOS, A. Isso (não) é muito Black Mirror: passado, presente e futuro das tecnologias de comunicação e informação. Salvador: EDUFBA, 2018.

LEMOS, A. A comunicação das coisas: teoria ator-rede e cibercultura. São Paulo: Editora Annablume. 2013.

LÓPEZ, T. S. et al. Taxonomy, technology and applications of smart objects. Inf Syst Front, v. 13, n. 2 , p. $281 / 300,2011$.

MAKEY MAKEY Disponível em: < https://makeymakey.com > . Acesso em : 30 nov. de 2018.

OXFORD DICTIONARY Disponível em:

<https://www.lexico.com/en/definition/cybernetics>. Acesso em : 10 nov. de 2018.

SANTAELLA, L. Pós-humano: Por quê? Revista USP, São Paulo, n. 74, p. 126-137, jun./ago. 2007.

SANTOS, E. Pesquisa-formação na cibercultura. Santo Tirso-PT: White books, 2014.

SANTOS, T. Computação Ubíqua para apoiar a Educação Musical: Explorações com Tapetes Musicais Inteligentes. 212 pgs. Dissertação (Mestrado em Informática) —Universidade Federal do Estado do Rio de Janeiro (UNIRIO), Rio de Janeiro, 2015.

SANTOS, T. M.; PIMENTEL, M.; FILIPPO, D. Tapetes Musicais Inteligentes: Computação Ubíqua para apoiar a Educação Musical. Revista Brasileira de Informática na Educação, v. 24, n. 2, 2016. 
SANTOS, T. M. Novas interfaces tecnológicas: discutindo os usos didáticos de uma roupa computacional para aulas de música. 2012. Dissertação (Licenciatura em Música) — UNIRIO, Rio de Janeiro, 2012.

WEISER, M. The computer for the twenty-first century. Scientific American, v. 65, n. 3, p. 94-104, 1991.

WEISER, MARK AND SEELY, BROWN JOHN. The coming age of calm technology [1] XEROX PARC OCTOBER 5, 1996.

RECEBIDO: 08/07/2019

APROVADO: 10/09/2019
RECEIVED: 08/07/2019

APPROVED: $10 / 09 / 2019$
RECIBIDO: 08/07/2019

APROBADO: 10/09/2019 